\title{
Preschooler's physical activity levels and associations with lesson context, teacher's behavior and environment during preschool physical education
}

Citation for published version (APA):

van Cauwenberghe, E., Labarque, V., Gubbels, J. S., de Bourdeaudhuij, I., \& Cardon, G. (2012). Preschooler's physical activity levels and associations with lesson context, teacher's behavior and environment during preschool physical education. Early Childhood Research Quarterly, 27(2), 221-230. https://doi.org/10.1016/j.ecresq.2011.09.007

Document status and date:

Published: 01/01/2012

DOI:

10.1016/j.ecresq.2011.09.007

Document Version:

Publisher's PDF, also known as Version of record

Document license:

Taverne

Please check the document version of this publication:

- A submitted manuscript is the version of the article upon submission and before peer-review. There can be important differences between the submitted version and the official published version of record.

People interested in the research are advised to contact the author for the final version of the publication, or visit the DOI to the publisher's website.

- The final author version and the galley proof are versions of the publication after peer review.

- The final published version features the final layout of the paper including the volume, issue and page numbers.

Link to publication

\footnotetext{
General rights rights.

- You may freely distribute the URL identifying the publication in the public portal. please follow below link for the End User Agreement:

www.umlib.nl/taverne-license

Take down policy

If you believe that this document breaches copyright please contact us at:

repository@maastrichtuniversity.nl

providing details and we will investigate your claim.
}

Copyright and moral rights for the publications made accessible in the public portal are retained by the authors and/or other copyright owners and it is a condition of accessing publications that users recognise and abide by the legal requirements associated with these

- Users may download and print one copy of any publication from the public portal for the purpose of private study or research.

- You may not further distribute the material or use it for any profit-making activity or commercial gain

If the publication is distributed under the terms of Article $25 \mathrm{fa}$ of the Dutch Copyright Act, indicated by the "Taverne" license above, 


\title{
Preschooler's physical activity levels and associations with lesson context, teacher's behavior, and environment during preschool physical education
}

\author{
Van Cauwenberghe Eveline ${ }^{\mathrm{a}, *}$, Labarque Valery ${ }^{\mathrm{b}}$, Gubbels Jessica ${ }^{\mathrm{c}}$, De Bourdeaudhuij Ilse ${ }^{\mathrm{a}}$, Cardon Greet ${ }^{\mathrm{a}}$ \\ a Department of Movement and Sport Sciences, University of Ghent, Watersportlaan 2, 9000 Ghent, Belgium \\ ${ }^{\mathrm{b}}$ HUBrussel (part of association KULeuven), Research Centre PRAGODI, Campus Nieuwland, Nieuwland 198, 1000 Brussels, Belgium \\ ' Department of Health Promotion, Maastricht University Medical Centre, PO Box 616, 6200 MD Maastricht, The Netherlands
}

\section{A R T I C L E I N F O}

\section{Article history:}

Received 6 October 2010

Received in revised form

16 September 2011

Accepted 27 September 2011

\section{Keywords:}

Preschool child

Structured physical activity

ActiGraph accelerometer

System for Observing Fitness Instruction Time

\begin{abstract}
A B S T R A C T
Preschools offer two main opportunities, recess and physical education (PE), for preschool children to participate in physical activity (PA) and are considered a suitable institution for PA promotion given the large number of children enrolled. Although PE can have a meaningful effect on preschoolers' PA levels, preschool PE characteristics associated with increased PA have, to the best of our knowledge, not been identified. Therefore, the purpose of the present study was to examine preschooler's PA levels and the associations with lesson context, teacher behavior, and environment during preschool physical education. A random sample of 573 preschoolers ( 288 boys; $M_{\mathrm{age}}=5.4$ years, $S D=0.4$ ) from 35 preschools was examined during one PE class. Findings indicated that preschoolers accumulated $12 \mathrm{~min}(33 \%)$ of moderate-to-vigorous PA (MVPA), $5 \mathrm{~min}$ (13\%) of light PA, and $20 \mathrm{~min}(54 \%)$ of sedentary behavior during PE. Forty-seven percent of the variance in pupils' MVPA may be attributed to differences between PE classes. Less knowledge content, less promotion, less management, less preschoolers per $100 \mathrm{~m}^{2}$, using obstruction material, and not using throwing equipment were significantly associated with higher MVPA levels. These predictors explained 56\% of the variance in MVPA at the PE class-level. To conclude, PE in its current format contributes only a small amount to the PA requirements of preschoolers. Preschoolers' MVPA levels were related to modifiable PE characteristics indicating that preschool PE can be restructured to increase MVPA.
\end{abstract}

(c) 2011 Elsevier Inc. All rights reserved.
The prevalence and degree of overweight and obesity in preschool children (3- to 5-year olds) is increasing worldwide (Roelants, 2009; Wang, 2006). Consequently, the pediatric obesity epidemic has heightened interest in physical activity (PA) during early childhood as a correlate of energy balance and body composition. High PA levels at the preschool ages are recognized as a potential protective factor against developing excessive weight gain later in life (Janz et al., 2009; Moore, 2003). Furthermore, PA participation in preschool-aged children contributes to the musculoskeletal, motor skill, and psycho-social development of preschool children (Janz et al., 2010; Lobo \& Winsler, 2006; Williams, 2008) and some studies have shown that PA behaviors are established during the preschool years (Herman, Craig, Gauvin, \& Katzmarzyk, 2009; Janz, Burns, \& Levy, 2005).

\footnotetext{
* Corresponding author. Tel.: +329 26463 35; fax: +32 92646484. E-mail addresses: Eveline.VanCauwenberghe@UGent.be (V.C. Eveline), Valery.Labarque@HUBrussel.be (L. Valery), Jessica.Gubbels@GVO.unimaas.nl (G. Jessica), Ilse.DeBourdeaudhuij@UGent.be (D.B. Ilse), Greet.Cardon@UGent.be (C. Greet).
}

In line with the acknowledgement that regular PA is critical to the health and development of young children, governments and professional groups have developed PA recommendations for preschool children. The National Association for Sport and Physical Education (NASPE) recommends at least $1 \mathrm{~h}$ per day of structured PA and at least $1 \mathrm{~h}$, and up to several hours per day, of unstructured play time (Clark et al., 2009). In 2009, the Australian Government's Department of Health and Aging released the recommendation that preschool-aged children should engage in a minimum of $3 \mathrm{~h}$ of PA every day (Department of Health and Aging (DOHA), 2009). Nevertheless, a limited but fairly consistent body of evidence suggests that preschool children generally participate in low levels of PA and relatively few preschoolers achieve sufficient PA (Oliver, 2007; Reilly, 2008; Tucker, 2008).

Worldwide and increasing use of organized out-of-home care (e.g., preschool, child care center, and family child care home) and the considerable time spent at such sites have led to an emerging interest in these settings as important contributions to the welfare and health of preschoolers (Hinkley, Crawford, Salmon, Okely, \& Hesketh, 2008; Ward, 2010). Despite the recognized value of out-of-home care settings for the early development of healthy 
behaviors, including PA, a recent review concluded that PA levels are typically very low during out-of-home care attending hours, and PA levels show great variability between and within these settings (Reilly, 2010). In summary, these arguments support that the out-of-home care environment is an ideal institution for PA promotion in preschoolers (Hinkley et al., 2008; Reilly, 2010; Ward, 2010). To guide the development of PA interventions at out-of-home care settings, it is, therefore, important to identify which features best promote regular PA in these settings (Hinkley et al., 2008; Trost, Ward, \& Senso, 2010).

In Flanders, the Dutch speaking part of Belgium, almost all elementary schools have a public preschool program (2213 schools with a preschool program; 95\%). The preschool programs are free and virtually all preschool children attend (191,155 preschoolers; 98\%) (Flemish Ministry of Education and Formation, 2011c). The preschools run from Mondays until Fridays and preschoolers spend approximately $30 \mathrm{~h}$ per week at preschool. Flemish preschools, and preschools in many other countries, offer two main opportunities to help young children obtain the necessary amount of PA during a preschool-attending day. First, unstructured opportunities during several recess periods every day and second, structured opportunities during physical education (PE) classes are provided (Bower et al., 2008; De Martelaer, Cools, Samaey, \& Andries, 2007; Vale, Santos, Soares-Miranda, Silva, \& Mota, 2011). Although researchers have begun to explore the specific recess policies, playground attributes, and environmental characteristics associated with increased PA (Trost et al., 2010), preschool PE characteristics positively influencing PA have, to the best of our knowledge, not yet been identified. Research in this area deserves further study as two recent studies indicated that PE might have a meaningful effect on preschool children's PA level (Bower et al., 2008; Vale et al., 2011). The study of Vale et al. (2011) established that preschool PE is effective in increasing Portuguese preschoolers' total PA and MVPA during preschool hours. Similar results were found in the study of Bower et al. (2008), examining the association between US childcare characteristics and preschooler's PA. The results showed that the 'Active Opportunities subscale,' including occasions of structured PA, occasions of outdoor play, and minutes of active opportunities, was related most strongly to all measures of PA while in child care (Bower et al., 2008).

During elementary school PE, PA levels have been found to be associated with how the lesson was delivered (lesson context), what the teacher was doing during the lesson (teacher behavior), and the PE environment (Chow, McKenzie, \& Louie, 2008; McKenzie et al., 1995; The National Institute of Child Health and Human Development Study of Early Child Care and Youth Development Network (NICHD SECCYD), 2003). As a result, a first purpose of the present cross-sectional study was to document the PA levels, the lesson context, the teacher's behavior, and the environment during PE at Flemish preschools. Based on the reports of low PA levels during PE in older children (Cardon, Verstraete, De Clereq, \& De Bourdeaudhuij, 2004; NICHD SECCYD, 2003) and given the multiple objectives of preschool PE in Flanders (the development of motor competence, a fit, healthy, and safe lifestyle, and a positive self-image and social skills) (De Martelaer et al., 2007), the researchers expected rather low PA levels during PE. PE classes in Flanders are conducted by classroom teachers (certified elementary school teachers, who are not PE specialized) or PE specialists. Previous studies found differences between PE classes taught by classroom teachers or PE specialists (McKenzie et al., 1995; NICHD SECCYD, 2003) and a second purpose of this study was, therefore, to investigate differences in PA levels, lesson context, and teacher's behavior between PE classes taught by classroom teachers or PE specialists. Further, to be able to use PE as a valuable strategy to increase PA levels in preschoolers, a third purpose was to reveal which specific lesson contexts, teacher behaviors, and environmental characteristics are associated with the PA levels during PE and to examine how much of the variance in PA during PE is explained by all these factors.

\section{Method}

\subsection{Participants}

Fifty-nine preschools from three Flemish regions were randomly selected from the official database of the Flemish government including all preschools in Flanders, Belgium (Flemish Ministry of Education and Formation, 2011b). The principals were contacted by phone and 35 (59.3\%) were willing to cooperate in the study. Within each preschool, all parents of the oldest children attending Flemish preschools (5- to 6-year olds) were invited to enroll their child in the present study $(n=722)$. Prior to data collection, written informed consent forms were obtained from the parents and the study was approved by the Ethics Committee of the University Hospital of Ghent. Informed consents from 651 parents (90.2\% of eligible children) were received. Due to absence on the day of measurements, 25 preschoolers dropped out. Further, 40 randomly chosen preschoolers could not participate in the study because of a limited number of accelerometers available. Finally, 586 preschoolers ( 295 boys; $M_{\text {age }}=5.4$ years, $S D=0.4$ ) from 35 preschools were measured during one PE class. Of the total sample, another two were excluded because of accelerometer failure and another 11 did not wear the accelerometer during the entire PE class, resulting in a final sample of 573 preschoolers ( 288 boys; $M_{\mathrm{age}}=5.4$ years, $S D=0.4$; range 4.0-6.9) from $35 \mathrm{PE}$ classes (5-35 preschoolers within a PE class). To align as closely as possible to the real-life situation, children without informed consent did attend the PE class but they did not wear an accelerometer during PE and they were not selected for the SOFIT analyses. One PE class (22 pupils) was excluded from the evaluation of the behavior of the teacher because audio was unsuccessfully recorded during this PE class. The PE classes were delivered by the classroom teacher ( $n=21$; all women) or a PE specialist ( $n=14 ; 7$ men). The median years of experience of the teacher was 5 (IQR: $3-17$ years).

\subsection{Procedure}

The preschoolers were studied during one PE class at preschool. Data collection was conducted in three phases due to logistical reasons: from October 2006 till February 2007, from October 2008 till February 2009, and from October 2009 till February 2010. Consequently, all PE classes were given indoors. Visits were arranged a week or more in advance by a researcher in conjunction with the PE teacher. Teachers were asked to deliver their normal lesson content and were not told that the lesson context and their teaching behavior would be coded. One hour before the start of the PE class, one video camera (Sony Digital Handycam DCR-PC101E) was positioned in the instructional area and accelerometers were fitted at the right side of the preschooler's hip, secured on an elastic belt, by a researcher. During the PE class, start and ending time, number of pupils, number of fixed equipment items used (e.g., climbing frames, balance beams, and basketball hoops), and whether throwing (e.g., balloons, tennis balls, and Frisbees), jumping (e.g., skipping-ropes and kangaroo balls), and obstruction (e.g., tunnels and portable soft construction blocks) equipment and bicycles were used, were recorded by a researcher. When the class was finished, accelerometers were collected by a researcher and the PE teacher's demographics (education and year of graduation) were obtained by a verbal questionnaire led by the researcher and pupils' demographics (gender and date of birth) were acquired 
from the preschool's database. To conclude, the perimeter of the instructional area was measured by a researcher using a tape measure.

\subsection{Instruments}

\subsubsection{GT1M ActiGraph accelerometer}

Pupils' PA levels were objectively measured using the GT1M ActiGraph accelerometer, a uni-axial accelerometer designed to detect vertical accelerations (Pate, O'Neill, \& Mitchel, 2010). ActiGraph accelerometers have established utility, validity, and reliability in preschool-aged children (Pate et al., 2010). Accelerometers were programmed to start measuring before the start of the PE class and to record vertical accelerations (accelerometer counts) every $15 \mathrm{~s}$ ( $15 \mathrm{~s}$ epoch).

\subsubsection{System for Observing Fitness Instruction Time}

The System for Observing Fitness Instruction Time (SOFIT) is a class-level observation system. SOFIT uses a three-phase decision system to obtain information on: (1) preschoolers' PA levels, (2) how PE time was allocated to various tasks and goals (lesson context), and (3) how teachers spent their time during PE (teacher's behavior) (McKenzie, Sallis, \& Nader, 1991). The first phase involved coding preschoolers' PA levels on a 1-5 scale (1: lying down; 2: sitting; 3: standing; 4: walking, and 5: vigorous). The SOFIT activity categories have been validated for use with energy expenditure estimates (Honas et al., 2008), heart rates (McKenzie, 1991), pedometers (Scruggs et al., 2003), and accelerometers (Pope, 2002). Secondly, the concurrent lesson context was coded based on whether lesson time is being allocated for general content (e.g., team selection and changing equipment), knowledge content (e.g., rules and techniques), fitness activities (e.g., dance and warm up), skill practice (e.g., dribbling and dance steps), game play (e.g., tag games and ball games), or free play. Finally, what the teacher was doing during the observation interval was coded into promotes fitness (e.g., prompts and encouragements), demonstrates fitness (e.g., demonstrating and participating), instructs generally (e.g., describes activity and provides feedback), manages (e.g., setting up equipment and directing pupils), observes (e.g., monitoring class or individual), or other task (e.g., reading newspaper and making phone call).

SOFIT has been widely used for measuring PA levels of children during PE (Chow et al., 2008; McKenzie et al., 1995; NICHD SECCYD, 2003). Nevertheless, to the best of our knowledge, it is the first time that SOFIT was used to evaluate PE at the preschool-level. Standard guidelines in the SOFIT manual (McKenzie, 2009) were followed except that observations were not performed during the PE class itself but on the obtained video footage using the direct observation software Vitessa .1 (Van Puyenbroeck et al., 2009). Four pupils were randomly selected from each class (alternately a boy and a girl) and were observed for 12 periods of $20 \mathrm{~s}$ on a rotational basis. Ten seconds observing were alternated with 10 s recording. In line with the SOFIT protocol, preschoolers' PA levels and the lesson context were coded at the end of the observation interval while the teacher's behavior was coded based on the entire observation interval. The observation started when the teacher and at least $51 \%$ of the pupils had reached the instructional area and ended when half of the pupils had departed from the area. Before data collection, two observers were engaged in a training protocol for $40 \mathrm{~h}$, including reading SOFIT articles, studying observation procedures, practicing and discussing coding definitions, and individual coding of four preschool PE classes (439 observation intervals) to assess reliability. Interobserver agreement scores, using stringent interval-by-interval comparisons, indicated agreements of $84 \%$, $89 \%$, and $81 \%$, respectively, for pupil's activity level, lesson context, and teacher's behavior. According to the SOFIT manual (McKenzie,
2009), these reliability scores were sufficient. The remaining 31 videos were coded by one observer.

\subsection{Measures}

1.4.1. Physical activity levels, lesson context, teacher's behavior, and environment during preschool physical education

After data collection, accelerometers were downloaded and subsequently the accelerometer data reduction software Meterplus 4.0 was used to clean and score the accelerometer data (Santech Inc, 2010). First, the start and stop times of PE were applied to extract the corresponding accelerometer data. Following, accelerometer counts per epoch (CPE) were converted to minutes and percentage of PE time in sedentary, light, moderate, and vigorous PA using recently developed $15 \mathrm{~s}$ GT1M ActiGraph cut points specifically developed for preschoolers (Van Cauwenberghe, Labarque, Trost, De Bourdeaudhuij, \& Cardon, 2011). In addition, as a measure of pupils' total PA during PE, mean CPE during PE was calculated. The obtained SOFIT data (3905 observation intervals) were aggregated into class totals (35 PE classes), namely, the absolute and the percentage of PE class time spent in the various activity levels, lesson contexts, and teacher behaviors. According to the SOFIT manual (McKenzie, 2009), activity code 4 (walking) and activity code 5 (vigorous) were summed to obtain the time spent in MVPA. Further, mean SOFIT activity level during each class was calculated as a measure of the total PA level during each class. The observed class length, class size, number of preschoolers per $100 \mathrm{~m}^{2}$, number of fixed equipment items used, and the use of throwing, jumping, and obstruction equipment and bicycles were also described.

\subsubsection{Associations between physical education characteristics and physical activity levels during preschool physical education}

Consistent with previous research, percentage of PE class time in MVPA served as the dependent variable (Chow et al., 2008; McKenzie et al., 1995; NICHD SECCYD, 2003). The accelerometerdetermined MVPA levels of each preschool child were included as the dependent variable but not the SOFIT-determined MVPA levels of each PE class. The accelerometer-determined MVPA levels were preferable because they enable us to determine the associations with MVPA at the pupil-level while the SOFITdetermined MVPA levels only allow us to investigate the associations with MVPA at the class-level. Independent variables were the SOFIT-determined percentage of PE class time spent in the various lesson contexts, teacher behaviors, and the observed class length, class size, number of preschoolers per $100 \mathrm{~m}^{2}$, number of fixed equipment items used and the use of throwing, jumping, and obstruction equipment, and bicycles.

\subsection{Statistical analyses}

Preliminary analyses consisted of descriptive statistics of the sample, the PA levels, the teacher behaviors, the lesson contexts, and the environment. Paired samples $t$-tests were conducted to examine differences between accelerometer-based and SOFIT-based MVPA levels. Pearson's correlations between mean accelerometer CPE and mean SOFIT activity level during each PE class and between accelerometer-based and SOFIT-based MVPA levels during each PE class were calculated to evaluate the validity of the SOFIT measurements. Independent samples $t$-tests were conducted to investigate differences in PA levels, lesson context, and teacher's behavior between classes taught by classroom teachers and PE specialists. All analyses were calculated with SPSS for Windows 15.00 .

Two-level (pupils within PE classes) univariate regression analyses, using MLwiN 2.16 (Rasbash et al., 2009), were conducted to 
investigate the relationship between the percentage of time pupils spent in MVPA during PE and lesson context, teacher's behavior, and environment (Hox, 2002; Rasbash et al., 2009). Estimation of parameters was performed with the maximum likelihood algorithm. Prior to analyses, the measured predictors were checked for normal distribution (skewness $>0.7$ ). For six variables, values higher than the 90th percentile were replaced by the value that equalizes the 90th percentile, to obtain a normal distribution. These six variables were years of experience, class size, number of preschoolers per $100 \mathrm{~m}^{2}$, the percentage of class time spent in fitness activities and game play, and the percentage of class time the teacher spent in observing. Three predictors were ultimately excluded because they did not obtain a normal distribution, namely the percentage of class time spent in other tasks and the use of jumping equipment and bicycles. Given the possibility that variations in year of data collection might alter results reported, Pearson correlations between the year of data collection and the predictors were calculated. No statistical significant correlations were found and all analyses were, therefore, not controlled for year of data collection. Second, interaction effects between the pupils' and teachers' demographic characteristics (pupils' gender and age and teachers' education and years of experience) and the predictors were examined. As none of the interaction effects reached significance, only main effects were investigated. Subsequently, the intercepts-only model was controlled for pupils' and teachers' demographic characteristics. Following, three sets of regression models with mean-centered predictors were constructed. Model 1 included seven predictors, namely the seven lesson context variables (class length, the percentage of class time spent in general content, knowledge content, fitness activities, skill practice, game play, and free play), model 2 included five predictors, namely the five teacher behavior variables (the percentage of class time the teacher spent in promoting, demonstrating, instructing, managing, and observing) and model 3 included five predictors, namely the five environmental variables (class size, number of preschoolers per $100 \mathrm{~m}^{2}$, number of fixed game equipment items used, and the use of throwing and obstruction equipment). Before conducting the regression analyses, variables were tested for multicollinearity (Pearson correlation $>0.60$ ). Multicollinearity was found between the percentage of class time spent in general content and skills practice and between the percentage of class time spent in skills practice and game play in model 1 . In model 2, multicollinearity was found between the percentage of class time the teacher spent in demonstrating and instructing. In model 3, there were no problems of multicollinearity. Following, the percentage of class time spent in general content and game play were excluded from model 1 and the percentage of class time the teacher spent in demonstrating was excluded from model 2 because these predictors correlated the least with the dependent variable, namely pupils' MVPA levels during PE. As a result, the following three sets of regression models were tested: model 1 with five predictors (class length, the percentage of class time spent in knowledge content, fitness activities, skill practice, and free play), model 2 with four predictors (the percentage of class time the teacher spent in promoting, instructing, managing, and observing), and model 3 with five predictors (namely class size, number of preschoolers per $100 \mathrm{~m}^{2}$, number of fixed game equipment items used, and the use of throwing and obstruction equipment). Predictors that were not statistically significant, were removed from model 1,2 , and 3 one at a time, starting with the least significant one. Finally, the identified significant predictors in model 1,2 , and 3 were entered into one regression model (model 4). Again, the included variables were tested for multicollinearity and no problems were found. For all analyses, $p$ values of 0.05 were considered as significant.
Table 1

Physical activity levels during preschool physical education using accelerometry and the System for Observing Fitness Instruction Time.

\begin{tabular}{lcl}
\hline $\begin{array}{l}\text { Pupils' PA levels using } \\
\text { accelerometry }(n=573 \text { pupils } \\
\text { within 35 PE classes) }\end{array}$ & Mean min $(S D)$ & $\begin{array}{l}\text { Mean \% of PE } \\
\text { class time }(S D)\end{array}$ \\
\hline Sedentary & $20.4(7.0)$ & $53.7(13.8)$ \\
Light & $5.0(2.2)$ & $13.3(5.9)$ \\
Moderate & $5.0(2.1)$ & $13.4(5.1)$ \\
Vigorous & $7.4(3.9)$ & $19.6(9.5)$ \\
MVPA (moderate+ vigorous) & $12.4(5.1)$ & $33.0(12.1)$ \\
& & \\
Class measure of PA & Mean min $(S D)$ & Mean \% of PE \\
levels using SOFIT & & class time (SD) \\
(n=35 PE classes) & & $3.0(4.7)$ \\
\hline Lying down & $1.1(1.7)$ & $27.8(16.5)$ \\
Sitting & $10.4(6.1)$ & $23.4(10.0)$ \\
Standing & $8.7(3.7)$ & $27.7(11.0)$ \\
Walking & $10.3(4.1)$ & $18.1(9.6)$ \\
Vigorous & $6.7(3.6)$ & $45.8(13.8)$ \\
MVPA (walking + vigorous) & $17.1(5.1)$ &
\end{tabular}

Note: PA, physical activity; $n$, sample size; PE, physical education; min, minutes; MVPA, moderate-to-vigorous physical activity; SOFIT, System for Observing Fitness Instruction Time.

\section{Results}

\subsection{Physical activity levels during preschool physical education}

The descriptive data of the PA levels of the pupils, using accelerometry, and of the PE class, using SOFIT, can be found in Table 1. According to the accelerometer data, pupils' average total PA during PE was 481.9 CPE ( $S D=148.8)$ while the mean PA intensity level during PE according to SOFIT (scale $1-5)$ was $3.3(S D=1.1)$. A significant positive correlation was found between the mean accelerometer CPE and the mean SOFIT activity intensity level during each PE class $(r=0.49, p=0.003 ; n=35)$. Paired samples $t$ tests indicated that the classified proportion of PE time in MVPA (mean difference of $-13.0 \% ; t=6.68 ; d f=34 ; p<0.001$ ) was significantly lower according to the accelerometer data compared to the SOFIT data. Positive significant correlations were found between accelerometer-based and SOFIT-based MVPA $(r=0.56 ; p<0.001$; $n=35$ ) during each PE class. PE classes taught by PE specialists and classroom teachers were not significantly different from each other in terms of SOFIT PA levels (all $p>0.05$ ). Using the accelerometer data, the proportion of time spent in light PA was significantly higher in PE classes taught by PE specialists compared to PE classes taught by classroom teachers (mean difference of $2.2 \% ; t=3.68$; $d f=260 ; p<0.001$ ) while vigorous PA (mean difference of $-1.6 \%$; $t=-1.97 ; d f=571 ; p=0.05$ ) and MVPA levels (mean difference of $-2.4 \% ; t=-2.36 ; d f=479 ; p=0.02$ ) were significantly lower in PE classes taught by PE specialists compared to PE classes taught by classroom teachers. No significant differences were found for sedentary behavior and moderate PA (all $p>0.05$ ).

\subsection{Lesson context during preschool physical education}

The average PE class length was $37.8(S D=7.1)$ min (range 22.0-62.0 min). Table 2 shows that skill practice was the lesson context that accounted for the largest proportion of time during $\mathrm{PE}$, followed by knowledge content, general content, game play, and fitness activities. No time was devoted to free play. Additionally, the percentage of time spent in MVPA and in each teacher behavior during each lesson context can be found in Table 2. No significant differences were found in the proportion of time spent in each lesson context between PE classes led by PE specialists or classroom teachers (all $p>0.05$ ). 


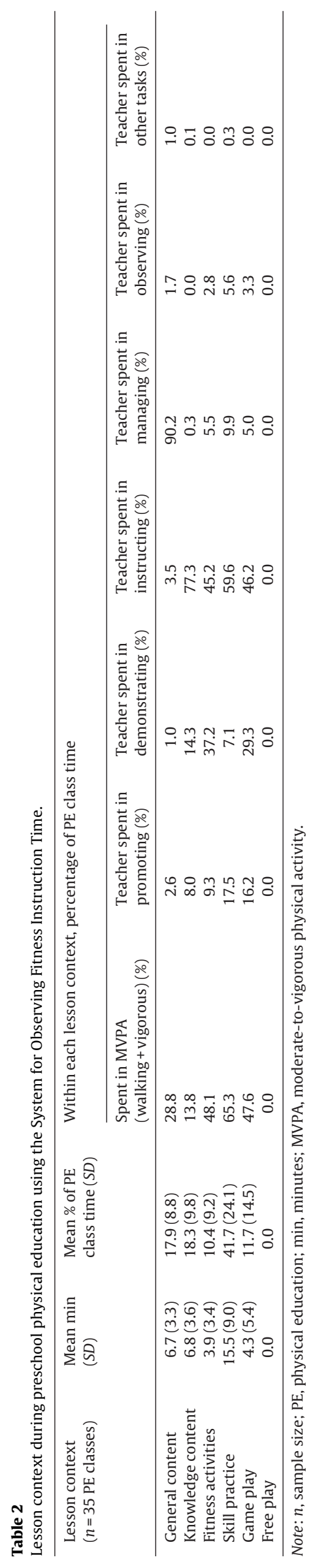

\subsection{Teacher behavior during preschool physical education}

Table 3 illustrates that during PE, the teacher spent almost half of the time in instructing, followed by managing, demonstrating, promoting, observing, and other tasks. Furthermore, the percentage of time spent in MVPA and in each lesson context during each teacher behavior is presented in Table 3. There were no significant differences in the proportion of time spent in each teacher behavior between PE classes taught by PE specialists or classroom teachers (all $p>0.05$ ).

\subsection{Environmental characteristics during preschool physical education}

The median number of preschoolers attending the PE class was 19 (IQR: 17-22) with a median of 12 pupils per $100 \mathrm{~m}^{2}$ (IQR: $8-17)$. The mean number of fixed game equipment items used was $3(S D=2$; range $0-8)$. In 20 (57.1\%) PE classes, throwing equipment was used, in seven (20.0\%) jumping equipment, in 15 (42.9\%) obstruction equipment, and in two (5.7\%) bicycles.

\subsection{Associations between physical education characteristics and physical activity levels during preschool physical education}

The intra-class correlation of the intercepts-only model indicated that $46.6 \%$ of the total variance in pupils' MVPA during PE may be attributed to differences between PE classes while $53.4 \%$ was explained by individual differences. When controlling for the pupils' and teachers' demographics, only pupil's gender $\left(\chi^{2}(\Delta\right.$ $1 d f)=5.51, p=0.02$ ) improved the overall fit of the interceptsonly model and further analyses were, therefore, controlled for the pupil's gender. The pupil's gender explained $1.0 \%$ of the variance in MVPA at pupil-level (Table 4).

When testing the three sets of regression models, four predictors (i.e., class length and the percentage of class time spent in fitness activities, skill practice, and free play) were excluded from model 1, two predictors (i.e., the percentage of class time the teacher spent in instructing and observing) were excluded from model 2, and two predictors (i.e., class size and the number of fixed game equipment items used) were excluded from model 3 as these predictors appeared to be non-significant. After removing these variables (Table 4 ), the overall fit of model 1,2 , and 3 improved significantly compared to the intercepts-only model controlled for pupil's gender $\left(\chi^{2}(\Delta 1 d f)=7.21, p=0.01 ; \chi^{2}(\Delta 2\right.$ $d f)=156.21, p<0.001 ; \chi^{2}(\Delta 3 d f)=18.12 p<0.001$, respectively $)$. In model 1 , more time devoted to knowledge content was significantly associated with less engagement in MVPA. Knowledge content explained $20.1 \%$ of the between-PE class variance in MVPA engagement (Table 4). In model 2 , significant inverse relationships were found between time spent in promotion and management and pupils' MVPA levels. Both variables explained $31.7 \%$ of the variance in MVPA at the PE class-level (Table 4). In model 3, more preschoolers per $100 \mathrm{~m}^{2}$, using throwing equipment, and not using obstruction equipment were associated with less time in MVPA. These variables explained $43.5 \%$ of the variance in MVPA at the PE class-level (Table 4). The final model, including all significant predictors from model 1,2 , and 3, improved significantly compared to the intercepts-only model controlled for pupil's gender $\left(\chi^{2}(\Delta\right.$ $6 d f)=169.08, p=0.01$ ). Significant associations were found with the environmental variables; more preschoolers per $100 \mathrm{~m}^{2}$, using throwing equipment, and not using obstruction equipment were associated with less time in MVPA. This model explained $56.0 \%$ of the variance in MVPA at the PE class-level. 


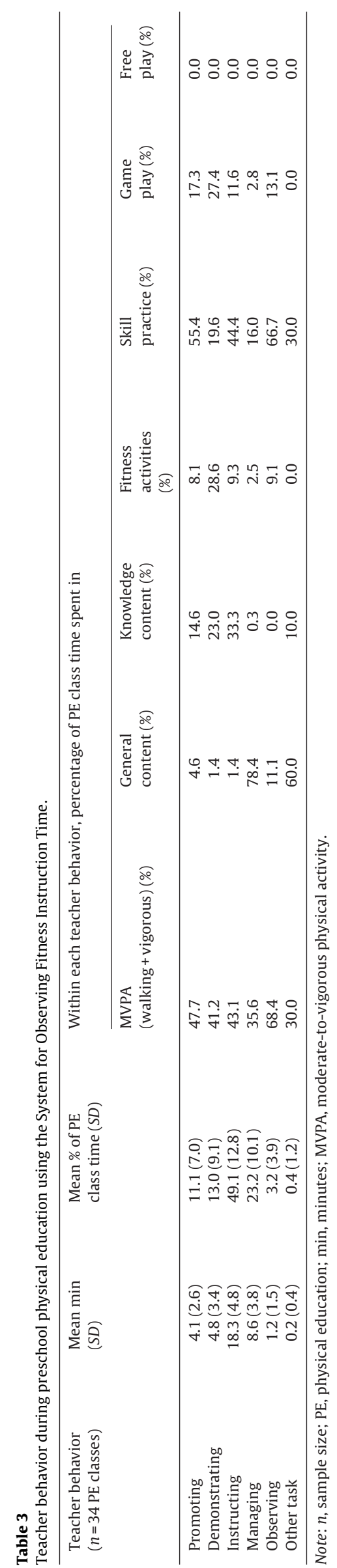

\section{Discussion}

\subsection{Physical activity levels during preschool physical education}

The present study is the first to describe PA levels of preschool children during preschool PE using accelerometry and SOFIT. Overall, using the accelerometer data, preschool children engaged for half of the PE time in sedentary behaviors (54\%; $20 \mathrm{~min}$ ) and almost half of the PE time in active behaviors ( $46 \% ; 17 \mathrm{~min}$ ), with $13 \%$ (5 min) in light, $13 \%$ (5 min) in moderate, and 20\% (7 min) in vigorous PA. The SOFIT class-level measure revealed that PE consisted of 3\% ( $1 \mathrm{~min}$ ) lying down, 28\% (10 min) sitting, 23\% (9 min) standing, and 46\% (17 min) MVPA, with 28\% (10 min) in walking and $18 \%$ (7 min) in vigorous PA. With lessons scheduled twice per week in Flemish preschools, pupils would typically accrue around $35 \mathrm{~min}$ in active behaviors, including $25 \mathrm{~min}$ in MVPA. This amount of PA equalizes only $11.7 \%$ of the recommended structured activity (i.e., 60 min per day for 5 days per week) (Clark et al., 2009). Even at best, PE in its current format cannot provide enough PA to meet the health-related PA recommendations. Although Belgium has a leading position regarding time allocated to $\mathrm{PE}$ in the preschool curriculum (De Martelaer et al., 2007) a higher frequency, intensity, and duration of PE classes may be required if PE wants to substantially increase children's total PA. This recommendation is in line with the NASPE's (National Association for Sport and Physical Education) guideline of 60 min structured PA a day (Clark et al., 2009). Yet, PE should not be implemented at the expense of children's free play (Clark et al., 2009). Besides, parents should create adequate opportunities for their preschool children to be physically active at home (Nyberg, Nordenfelt, Ekelund, \& Marcus, 2009).

Two different methods were used to measure PA levels during PE and it can be concluded that the accumulated time in MVPA during PE was different according to the pupils' accelerometer data and the class-level measure SOFIT. A first explanation for the discrepancy could be the inherent characteristics of both measurement methods. To obtain information on preschoolers' PA levels at PE class-level, SOFIT uses data from four randomly selected children while the accelerometer data is based on individual accelerometer data from virtually all the participants in the PE class. Another plausible explanation for the higher amount of MVPA according to SOFIT could be the SOFIT decision rules used for coding pupil's activity level. Activities of light intensity, such as slow walking, are, according to the SOFIT manual, coded as activity code 4 and are considered as MVPA (McKenzie, 2009). In 2002, Pope et al. revised the original SOFIT activity level coding system and suggested that a six-point scale, which distinguishes between moderate and light PA, may be more sensitive to measuring light and moderate PA during PE (Pope, 2002). The results from the present study confirm these findings but nevertheless it should be kept in mind that the original five-point scale, with clear and distinct categories, is easier to apply during PE than the six-point scale and is still recommended for use (McKenzie, 2009; Pope, 2002). Although significant differences were found between accelerometer-based and SOFITbased PA levels, acceptable correlations were found between these variables, indicating that SOFIT provides a rather valid group estimate of PA levels during PE. However, further research, specifically designed to establish the validity of SOFIT during preschool PE, is warranted.

\subsection{Lesson context and teacher behavior during preschool physical education}

Although, it was beyond the scope of the present study to evaluate the PE classes in terms of the extent to which the three objectives of preschool PE in Flanders (De Martelaer et al., 2007) have been reached, the SOFIT analyses did indicate that there was 
Table 4

Two-level univariate regression analyses of the associations between pupils' moderate-to-vigorous physical activity during preschool physical education and lesson context, teacher behavior, and environment.

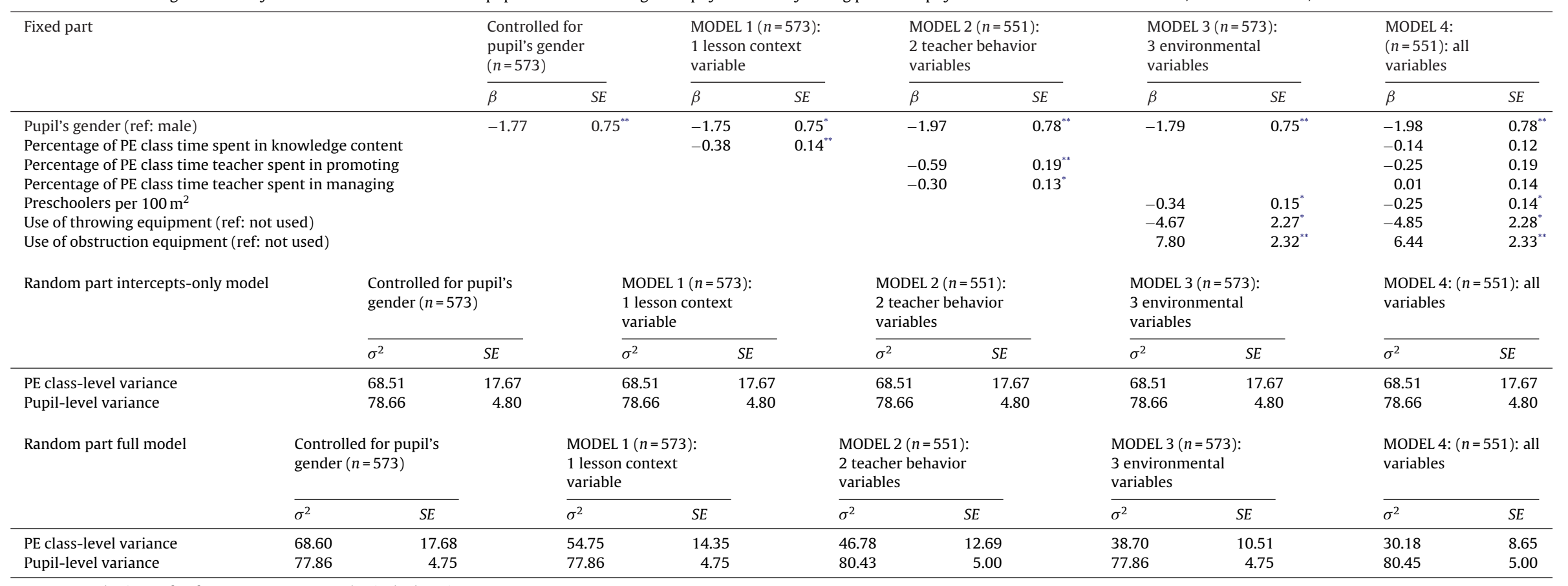

Note: $n$, sample size; ref, reference category; PE, physical education.

${ }_{* *}^{*} p<0.05$.

*** $p<0.01$ 
a main focus on the development of movement skills (manipulative and locomotor skills) which required that time was being allocated to knowledge (e.g., rules and techniques) and general content (e.g., team selection and changing equipment), and a teacher devoting time to instructions (e.g., describes activity and provides feedback) and management (e.g., setting up equipment and directing pupils). These lesson contexts and teacher behaviors were inherently associated with less engagement in MVPA and are consequently interfering with pupils' opportunities to be active during PE (the healthy lifestyle objective). Nevertheless, it should be emphasized that motor skill acquisition is essential during early childhood (Clark et al., 2009). Furthermore, it has been suggested that preschool children who are motor competent are also more physically active (Williams, 2008). With lessons scheduled twice per week, it is unlikely that preschool PE can fulfill all these objectives. Again, and similar to PE recommendations in older children (United States Department of Health and Human Services, 2000), more and longer PE lessons in the preschool curriculum might be recommended.

\subsection{Associations between physical education characteristics and physical activity levels during preschool physical education}

Another purpose of this study was to explore factors which might underlie pupils' MVPA levels during preschool PE. It was estimated that $47 \%$ of the variance in pupils' MVPA levels may be attributed to differences between PE classes. This finding, together with the relatively large standard deviations found in pupils' activity levels, lesson context, and teachers' behavior, indicate that there is a substantial variation in how PE is conducted in Flemish preschools and that there are opportunities to increase MVPA levels during preschool PE. Furthermore, these findings strongly suggest that there is a strong association between PE characteristics and preschoolers' MVPA behavior during PE.

Although the regression analyses revealed that pupil's gender was significantly associated with MVPA and partly explained the between-pupil variance in MVPA, the difference (i.e., $1 \mathrm{~min}$ ) and the explained variance (i.e., $1 \%$ ) were negligible. In summary, the present findings endorse that structured activity breaks, such as PE, have promise for encouraging quality PA behaviors in both girls and boys. In unstructured activity contexts, such as recess, it has been shown that children as young as preschoolers do demonstrate gender differences with boys exhibiting higher PA levels (Cardon, Van Cauwenberghe, Labarque, Haerens, \& De Bourdeaudhuij, 2008). In addition, preschooler's age was not associated with MVPA engagement during PE. This finding can probably be explained by the limited age range in the investigated population (4.0-6.9 years) and the fact that PA was structured. Further, it appeared that teacher's education and years of experience was not associated with preschoolers' MVPA levels during PE. Accordingly, significant but unmeaningful differences (i.e., $1 \mathrm{~min}$ ) were found in accelerometer-based PA levels during PE while no significant differences were found in lesson context and teacher behavior between PE classes taught by PE specialist or classroom teachers. In conclusion, the results indicate that both, teachers' education and years of experience were not associated with how PE was delivered. Since preschool PE programs are taught in Flanders by the classroom teacher or a PE specialists (De Martelaer et al., 2007), this is a positive finding. Nevertheless, future research is warranted to determine if there are any quality differences.

Investigating the association with the lesson context variables, indicated that preschoolers were more active during PE when less time was spent in knowledge content (e.g., rules and techniques). To improve MVPA levels during PE it can be suggested to consume as less time as possible on knowledge content or provide the knowledge content in an active way (e.g., pupils are standing up instead of sitting). In addition, the between-PE class variance in MVPA was highly (20\%) explained by this lesson context variable. How the lesson is delivered is thus an important PE characteristic related to MVPA engagement during PE. Another interesting finding is that lesson length was not associated with the proportion of PE time in MVPA levels, pointing out that longer lessons are not associated with decreased engagement in MVPA. During recess at preschool, contrasting results were found with shorter recesses related to increased step counts per minutes (Cardon et al., 2008). In the present study, PE class time varied from 22 to $62 \mathrm{~min}$. In Flanders, lessons are scheduled two times per week for $60 \mathrm{~min}$ in the preschool curriculum and therefore preschools and teachers should try to conduct the PE classes at least with the frequency and duration planned.

Negative associations were found between MVPA engagement and the time the teacher devoted to promotion (e.g., prompts and encouragements) and management (e.g., setting up equipment and directing pupils). This can be explained by the fact that promotion mainly occurred during skill practice (55\%) and probably resulted in the preschool child focusing more on the task rather than engaging in more MVPA. To achieve positive changes in MVPA levels during $\mathrm{PE}$, teachers need to be efficient class managers or try to actively involve the preschool children when managing (e.g., preschoolers can help with setting up the equipment; preschoolers can play freely when teacher is setting up the equipment). Thirty-two percent of the between-PE class variance in MVPA was explained, emphasizing the important role of teachers' behavior in PA promotion through PE.

Examining the association with the environmental variables, showed that less preschoolers per $100 \mathrm{~m}^{2}$ were related to greater percentages of time in MVPA during PE. Previous research has shown that also during recess at preschool, the space provided is an important predictor of PA (Cardon et al., 2008; Dowda, 2009). For playgrounds, it has been recommended that a minimum of $7 \mathrm{~m}^{2}$ of outdoor play area for each child should be available (Clark et al., 2009). In the present study, 15 out of 35 PE areas (43\%) did not meet this recommendation. The findings suggest that preschools with smaller PE areas may need to split their class groups or give their PE classes as much as possible outdoors where typically more space is available. Contradicting results have been found for the association between fixed and portable game equipment and playground PA at preschool (Cardon et al., 2008; Dowda, 2009). The present study showed that there was a relationship between the presence of throwing and obstruction equipment and participation in MVPA during PE. The presence of throwing equipment (e.g., balloons, balls, and Frisbees) was related to lower MVPA levels. The researchers observed that the presence of throwing equipment mostly co-occurred with the training of manipulative skills (e.g., throwing and catching) which are typically less active. On the other hand, the presence of obstruction equipment (e.g., tunnels and portable soft construction blocks) was associated with greater percentages of time in MVPA. It was observed by the researchers that obstruction equipment often co-occurred with the training of locomotor skills (e.g., crawling, hopping, and running) which are inherently more active. Therefore, PE teachers can make PE more active by training on locomotor skills and using appropriate game equipment. In line with the ecological framework, it appeared that the PE environment was an important characteristic as $44 \%$ of the between-PE class variance in MVPA was explained by the environmental characteristics.

The results of the final model, controlling for the different models of independent variables, demonstrated that only the environmental predictors remained significant. This endorses a previous finding of this study that the explained variance in MVPA at the PE class-level by the environmental variables was the highest. The same associations were found, namely less preschoolers 
per $100 \mathrm{~m}^{2}$, using obstruction material, and not using throwing equipment were linked to higher MVPA levels during preschool PE. Nevertheless, all the included predictors seem to be important as they explained 56\% of the variance in MVPA at the PE class-level, which is substantially higher than the explained variance of the three other models, including only one set of independent variables.

\subsection{Strengths and limitations}

A major strength of the present study was the use of two independent measures of PA during PE (Oliver, 2007). Accelerometry provided an objective measure of the time spent in the different PA intensities of each preschooler. On the other hand, SOFIT delivered a class measure of the accumulated time in different types and intensities of PA. The observations also permitted a direct assessment of how PE subject matter was provided and how teachers themselves behaved during PE. Secondly, a two-level design, taking into account the clustering of pupils within PE classes, in a relatively large sample was employed. A minimum of $30 \mathrm{PE}$ classes is recommended to estimate the variance in MVPA accounted for by PE class (Hox, 2002). Finally, the present findings are transferable to many other countries and become increasingly important as more and more preschoolers across the globe spend large amounts of time in out-of-home care and structured PA sessions, such as PE, are often delivered (Bower et al., 2008; De Martelaer et al., 2007; Vale et al., 2011). Further, the nature of out-of-home care is changing and now aims toward school readiness and outcomes such as basic literacy and numeracy (Flemish Ministry of Education and Formation, 2011a; Reilly, 2010). This trend probably introduced more sedentary behavior during an out-of-home care attending day and emphasizes the importance of active opportunities, both structured PA and free play, during attendance at these settings.

Some limitations of the present study need to be addressed. Although the GT1M ActiGraph accelerometer has established validity in preschool children, some types of activities cannot be captured by this single axis, hip-mounted accelerometer (e.g., bicycling and carrying a load). Secondly, while cross-sectional studies are valuable for identifying and understanding associations between preschooler's PA and attributes of PE, no evidence of causality could be obtained. Experimental studies are necessary to guide recommendations for PA promotion through PE and to be conclusive about causal directions. Furthermore, a great deal of PA during a preschool-attending day is likely to be accumulated outside PE. Future research should look into possible sources of variation in PA at different times during the day and across a number of settings and contexts. A third limitation is the collection of the data from late fall through winter, implicating that all PE classes were given indoors. Moreover, only one PE class was observed per teacher. The aforementioned limitations highlight that future research should observe several PE classes per teacher throughout the year to obtain a more representative sample. Additionally, to reduce reactivity of the teacher, the teacher did not wear a microphone during the observations, making it sometimes very difficult to understand the teacher. Finally, the regression models only included class-level variables, making it impossible to determine how much of the individual variation in MVPA was explained. Future investigation should include individual measures to gain more insight in the individual differences within PE classes.

\section{Conclusion}

To conclude, the present study was the first to describe PA levels, lesson context, teacher behavior, and environment during PE at the preschool-level. It appears that PE currently contributes only a small amount to the PA requirements. The regression analyses revealed that a great proportion of the variance between PE classes in MVPA was explained by modifiable factors, indicating that there are opportunities to increase PA levels during preschool PE. Less knowledge content, less management, more space, and increased use of obstruction equipment might easily improve the PA levels during structured PA sessions. Intervention studies at out-of-home care settings; aiming to increase the intensity and amount of PA in preschoolers through structured PA sessions, such as PE, should target the identified modifiable factors in the present study.

\section{Acknowledgements}

The present study was financially supported by grants from the Research Foundation - Flanders (FWO B/10525/01) and by a PWOgrant of HUBrussel from the Flemish Ministry of Economics, Science and Innovation. Eveline Van Cauwenberghe is a recipient of a PhDscholarship from the Research Foundation - Flanders (FWO) and Valery Labarque a recipient of a PWO-grant. The authors declare that the funding sources have had no input into the study design, data collection, analysis, and interpretation of the data, in the writing of the report or the decision to submit the paper for publication.

\section{References}

Bower, J. K., Hales, D. P., Tate, D. F., Rubin, D. A., Benjamin, S. E. \& Ward, D. S. (2008), The childcare environment and children's physical activity. American Journal of Preventive Medicine, 34, 23-29.

Cardon, G., Verstraete, S., De Clereq, D. \& De Bourdeaudhuij, I. (2004). Physical activity levels in elementary-school physical education: A comparison of swimming and nonswimming classes. Journal of Teaching in Physical Education, 23, 252-263.

Cardon, G., Van Cauwenberghe, E., Labarque, V., Haerens, L. \& De Bourdeaudhuij, I. (2008). The contribution of preschool playground factors in explaining children's physical activity during recess. International Journal of Behavioral Nutrition and Physical Activity, 5, 11.

Chow, B. C., McKenzie, T. L. \& Louie, L. (2008). Children's physical activity and environmental influences during elementary school physical education. Journal of Teaching in Physical Education, 27, 38-50.

Clark, J., Clements, R., Guddemi, M., Morgan, D., Pica, R., Pivarnik, J., et al. (2009). Active start: A statement of physical activity guidelines for children from birth to age 5(2nd ed.). Sewickley, PA: National Association for Sport and Physical Education.

De Martelaer, K., Cools, W., Samaey, C. \& Andries, C. (2007). De school als bron van mogelijkheden om fysieke actief te zijn in de kleuterfase. In L. Van Looy, M. Coninx, \& K. Lochtman (Eds.), Onderwijsonderzoek: redelijk eigenzinnig?! (Educational research: Reasonable self-willed?!) (pp. 191-206). Brussels, Belgium: VUBPRESS.

Department of Health and Aging (DOHA) (2009). Get up and grow: Healthy eating and physical activity for early childhood. Canberra: AU. Commonwealth of Australia. Retrieved from http://www.health.gov.au/internet/ main/publishing.nsf/content/EDFEDB588460BCE3CA25762B00232A13/\$File/ gug-directorscoord-2.pdf

Dowda, M. (2009). Policies and characteristics of the preschool environment and physical activity of young children. Pediatrics, 123, e261-e266.

Flemish Ministry of Education and Formation (2011a). Curriculum. Retrieved from http://www.ond.vlaanderen.be/dvo/

Flemish Ministry of Education and Formation (2011b). Onderwijsaanbod in Vlaanderen [Education in Flanders]. Retrieved from http://www.ond. vlaanderen.be/onderwijsaanbod/

Flemish Ministry of Education and Formation (2011c). Onderwijsstatistieken [Education Statistics]. Retrieved from http://www.ond. vlaanderen.be/onderwijsstatistieken/

Herman, K., Craig, C., Gauvin, L. \& Katzmarzyk, P. (2009). Tracking of obesity and physical activity from childhood to adulthood: The physical activity longitudinal study. International Journal of Pediatric Obesity, 4, 281-288.

Hinkley, T., Crawford, D., Salmon, J., Okely, A. D. \& Hesketh, K. (2008). Preschool children and physical activity: A review of correlates. American Journal of Preventive Medicine, 34, 435-441.

Honas, J., Washburn, R., Smith, B., Greene, J., Cook-Wiens, G. \& Donnelly, J. (2008). The System for Observing Fitness Instruction Time (SOFIT) as a measure of energy expenditure during classroom-based physical activity. Pediatric Exercise Science, $20,439-445$.

Hox, J. (2002). Multivlevel analysis: Techniques and applications. Mahwah, NJ: Erlbaum.

Janz, K., Letuchy, E. M., Eichenberger Gilmore, J. M., Burns, T. L., Torner, J. C., Willing, M. C., et al. (2010). Early physical activity provides sustained bone health benefits later in childhood. Medicine and Science in Sports and Exercise, 42, 1072-1078.

Janz, K. F., Burns, T. L. \& Levy, S. M. (2005). Tracking of activity and sedentary behaviors in childhood: The Iowa bone development study. American Journal of Preventive Medicine, 29, 171-178. 
Janz, K. F., Kwon, S., Letuchy, E. M., Eichenberger Gilmore, J. M., Burns, T. L., Torner, J. C., et al. (2009). Sustained effect of early physical activity on body fat mass in older children. American Journal of Preventive Medicine, 37, 35-40.

Lobo, Y. B. \& Winsler, A. (2006). The effects of a creative dance and movement program on the social competence of head start preschoolers. Social Development, $15,501-519$.

McKenzie, T. L. (1991). BEACHES: An observational system for assessing children's eating and physical activity behaviors and associated events. Journal of Applied Behavior Analysis, 24, 141-151.

McKenzie, T. L. (2009). SOFIT (System for Observing Fitness Instruction Time): Generic description and procedures manual. San Diego, US: School of Exercise and Nutritional Sciences, San Diego State University.

McKenzie, T. L., Feldman, H., Woods, S. E., Romero, K. A., Dahlstrom, V., Stone, E. J., et al. (1995). Children's activity levels and lesson context during third-grade physical education. Research Quarterly for Exercise and Sport, 66, 184-193.

McKenzie, T. L., Sallis, J. F. \& Nader, P. R. (1991). SOFIT - System for Observing Fitness Instruction Time. Journal of Teaching in Physical Education, 11, 195-205.

Moore, L. (2003). Does early physical activity predict body fat change throughout childhood? Preventive Medicine, 37, 10-17.

Nyberg, G. A., Nordenfelt, A. M., Ekelund, U. \& Marcus, C. (2009). Physical activity patterns measured by accelerometry in 6- to 10-yr-old children. Medicine and Science in Sports and Exercise, 41, 1842-1848.

Oliver, M. (2007). Physical activity in preschoolers: Understanding prevalence and measurement issues. Sports Medicine, 37, 1045-1070.

Pate, R. R., O'Neill, J. R. \& Mitchel, J. (2010). Measurement of physical activity in preschool children. Medicine and Science in Sports and Exercise, 42, 508-512.

Pope, R. (2002). Validity of a revised System for Observing Fitness Instruction Time (SOFIT). Pediatric Exercise Science, 14, 135-146.

Rasbash, J., Charlton, C., Browne, W. J., Healy, M., \& Cameron, B. (2009). MLwiN 2.16. Retrieved from http://www.cmm.bristol.ac.uk/MLwiN/index.shtml

Reilly, J. J. (2008). Physical activity, sedentary behaviour and energy balance in the preschool child: Opportunities for early obesity prevention. Proceedings of the Nutrition Society, 67, 317-325.

Reilly, J. J. (2010). Low levels of objectively measured physical activity in preschoolers in child care. Medicine and Science in Sports and Exercise, 42, 502-507.
Roelants, M. (2009). References for growth and pubertal development from birth to 21 years in Flanders, Belgium. Annals of Human Biology, 36, 680-694.

Santech Inc. (2010). Meterplus 4.2. Retrieved from http://www. meterplussoftware.com/

Scruggs, P. W., Beveridge, S. K., Eisenman, P. A., Watson, D. L., Shultz, B. B. \& Ransdell, L. B. (2003). Quantifying physical activity via pedometry in elementary physical education. Medicine and Science in Sports and Exercise, 35 1065-1071.

The National Institute of Child Health and Human Development Study of Early Child Care and Youth Development Network (NICHD SECCYD). (2003). Frequency and intensity of activity of third-grade children in physical education. Archives of Pediatrics and Adolescent Medicine, 157, $185-190$.

Trost, S. G., Ward, D. S. \& Senso, M. (2010). Effects of child care policy and environment on physical activity. Medicine and Science in Sports and Exercise, 42 $520-525$.

Tucker, P. (2008). The physical activity levels of preschool-aged children: A systematic review. Early Childhood Research Ouarterly, 23, 547-558.

United States Department of Health and Human Services. (2000). Healthy people 2010: Understanding and improving health. Washington, US: Government Printing Office.

Vale, S., Santos, R., Soares-Miranda, L. S., Silva, P. \& Mota, J. (2011). The importance of physical education classes in pre-school children. Journal of Paediatrics and Child Health, 47, 48-53.

Van Cauwenberghe, E., Labarque, V., Trost, S. G., De Bourdeaudhuij, I. \& Cardon, G. (2011). Calibration and comparison of accelerometer cut points in preschool children. International Journal of Pediatric Obesity, 6, e582-e589.

Van Puyenbroeck, J., Maes, B., \& Laeremans, P. (2009). Vitessa 0.1. Retrieved from http://ppw.kuleuven.be/ortho/vitessa

Wang, Y. (2006). Worldwide trends in childhood overweight and obesity. International Journal of Pediatric Obesity, 1, 11-25.

Ward, D. S. (2010). Physical activity in young children: The role of child care. Medicine and Science in Sports and Exercise, 42, 499-501.

Williams, H. (2008). Motor skill performance and physical activity in preschool children. Obesity, 16, 1421-1426. 